\title{
Finite element analysis of temperature distribution using ABAQUS for a laser-based tile grout sealing process
}

\author{
J Lawrence* and $\mathbf{L} \mathbf{L i}$ \\ Manufacturing Division, Department of Mechanical Engineering, University of Manchester Institute of Science and \\ Technology, Manchester, UK
}

\begin{abstract}
A finite element (FE) model has been developed utilizing the commercial ABAQUS package to determine the temperature distribution generated during the high-power diode laser (HPDL) processing of a novel ceramic tile grout seal, known as an amalgamated oxide compound grout (AOCG). The model was developed specifically to find the temperatures reached at the base of the ceramic tile grout seal, since temperatures in excess of $100^{\circ} \mathrm{C}$ must be attained so as to ensure certain chemical changes (the complete irreversibility of the water-glass reaction required by the process). Fourier's law and Laplace's equation were employed to build the temperature field equations under appropriate boundary conditions in two-dimensional coordinates, while the ABAQUS FE model was used to calculate the temperature field and model the thermal profile in the ceramic tile grout seal. Both the FE-generated thermal profiles and the resultant operating maps predicted temperatures and vitrification depths which were consistently higher than those obtained experimentally. Notwithstanding this, a comparison of the results revealed that the predicted depths of vitrification were in very close agreement with those observed on AOCG samples treated with the HPDL.
\end{abstract}

Keywords: high-power diode laser (HPDL), finite element, FE, ABAQUS, thermal profile, ceramic, grout, enamel

\section{NOTATION}

$k \quad$ thermal conductivity

$k_{x} \quad$ thermal conductivity in the $x$ direction

$k_{y} \quad$ thermal conductivity in the $y$ direction

$n \quad$ node

$q \quad$ generated heat flux

$Q \quad$ generated heat

$t \quad$ time

$T \quad$ surface temperature

$T_{\mathrm{i}} \quad$ surface temperature after laser beam interaction

$T_{\mathrm{o}} \quad$ original surface temperature

$\alpha \quad$ thermal diffusivity

$\tau_{i} \quad$ thermal boundaries $(i=1,2, \ldots, 8)$

$\nabla \quad$ three-dimensional operand

The MS was received on 12 April 1999 and was accepted after revision for publication on 15 October 1999.

*Corresponding author: Manufacturing Division, Department of Mechanical Engineering, UMIST, PO Box 88, Manchester M60 1QD, $U K$.

B02799 (C) IMechE 2000

\section{INTRODUCTION}

Ceramic tiles are considered to be one of the most cleanable surfaces available [1], and are applied to the walls and floors in a whole host of places. Currently, ceramic tiles are sealed with tile grout (typically epoxy based). A major difficulty with tiled surfaces is that contaminants can enter into and exit a space via a tiled surface, through the tile grouts used to fill the void between adjoining tiles [1]. Moreover, the predominant problem with commercially available tile grouts is that because they are organic based, porous and very difficult to clean, over time they become contaminated, and have to be removed physically or mechanically - an arduous and costly undertaking. A novel technique has been developed $[2,3]$ whereby a new tile grout was developed, namely the amalgamated oxide compound grout (AOCG), which, after high-power diode laser (HPDL) surface treatment, was sealed by means of the application of a vitreous enamal glaze which was fired using the HPDL.

The development of an accurate analysis procedure for many laser applications, including the ceramic tile grout 
sealing process, is extremely complicated due to the multitude of process parameters involved. Moreover, laser process parameters must be carefully selected in order to achieve satisfactory results. Thus the development of a suitable model to predict such changes can not only eliminate the need to perform experiments with every possible range of operating parameters, but can also provide information outside the range of operating parameters currently possible. Furthermore, mathematical modelling is required in order not only to predict the behaviour of the two-stage ceramic tile grout seal during processing with various laser parameters but also to investigate the basic process mechanisms in detail. In particular, it is needed to relate the physics of the thermal transfer process and the subsequent chemical changes within the interaction zone and its vicinity to the process parameters.

For many laser processes a large number of analytic models currently exist for the prediction of the thermal behaviour of materials during laser surface processing. These are mainly based on classic analytical solutions to temperature distribution derived by Jeager [4], Rosenthal [5], Carslaw and Jeager [6] and Patankar [7]. However, any model developed to predict the temperature profile in the two-stage ceramic tile grout seal should give the temperature profile throughout ceramic tiles and the substrate material at any stage during the process. In order to achieve this, the model developed can predict the temperature profiles in the materials during both the first and second stages of the ceramic tile grout sealing process, wherein the HPDL beam was incident on the untreated AOCG and the enamel frit. Because of the complex boundary conditions present in the two-stage ceramic tile grout seal, use of such analytical techniques is likely to be so involved and the computation so laborious, if possible at all, that a numerical method is the only feasible option.

The numerical method used was the software package ABAQUS, a commercially available general-purpose finite element (FE) package developed by HKS Inc. This selection was made on the grounds of the widespread availability of the package, its relative ease of use and, most importantly, because it produced the required thermal data in the desired format. Because of these attributes ABAQUS has been employed by a number of workers to model various laser materials processing techniques such as laser welding [8], laser brazing [9] and laser forming [10-12].

The principal mode of heat transfer examined in the model was conduction. This was mainly for reasons of simplification, but also because in the HPDL ceramic tile grout sealing process conduction appears to be the predominant heat transfer mechanism [13]. The primary aim of the analysis was to determine the temperatureinduced chemical changes that occur in the ceramic tile grout seal, in particular the AOCG, as a result of HPDL interaction. Thus, it is the condition of the ceramic tile grout materials after laser processing, and not necessarily during processing, from which it will be possible to obtain such information. However, in order to fully verify the model and ultimately obtain such information, the transient condition across the entire range of the heating cycle leading to the steady state condition is examined. Furthermore, the creation of a model that generates thermal contours rather than an isochromatic model allows time to be considered in an analysis, thus allowing the prediction of the effects of more laser parameters, such as traverse speed, into the final model. Also, thermocouple readings along with the results of the FE model revealed that during the second stage of the sealing process the maximum temperatures reached were consistently lower than those reached during the first stage [14]. Since no further thermally induced chemical reactions will occur as a result of the second stage of the process, its inclusion in this current study was not deemed necessary.

\section{CERAMIC TILE GROUT SEALING PROCESS}

Because of the attendant inadequacies of current commercially available tile grouts, a new grout was developed using a range of vitrifiable compounds in suitable ratios with other substances, and indeed with each other, in order to optimize the beneficial properties and reduce the detrimental properties of the constituent materials to form the AOCG. The composition of the AOCG is given elsewhere [2].

In order to form a manageable paste, the AOCG was mixed with approximately $50 \mathrm{wt} \%$ water-diluted sodium silicate solution. Sodium silicate solution, or water-glass as it is more commonly known, is a viscous colourless solution of colloidal sodium silicate. It is a silica-containing aqueous solution that, when combined with other solutions such as the AOCG, forms a gel-like mass of silicate hydrate. Such a mass remains soft and malleable until it is exposed to $\mathrm{CO}_{2}$ gas, either by means of a direct flow or through contact with the atmosphere, whereupon it hardens as a result of the complete hydrolysis of the dissolved sodium silicate by the reaction [15]

$$
\mathrm{Na}_{2} \mathrm{SiO}_{3}+\mathrm{CO}_{2} \rightarrow \mathrm{Na}_{2} \mathrm{CO}_{3}+\mathrm{SiO}_{2} \text { (colloidal) }
$$

Notwithstanding this, exposure of the hardened mass to water results in a reversal of the process and the mass returns to a gel-like state. However, heating the hardened mass in effect fires the water-glass (similar to that of a ceramic material) [15], increasing its strength and enabling it to withstand exposure to water.

The variations in thermal characteristics of the AOCG with increased temperature were investigated in terms of the compressive strength [2]. It was found that the strength of the AOCG in terms of increasing temperature 
is determined primarily by the water-glass, since the strength of the individual oxide compounds varies little or not at all at relatively low temperatures $\left(<500^{\circ} \mathrm{C}\right)$ [16]. Moreover, at temperatures above approximately $10{ }^{\circ} \mathrm{C}$ the complete irreversibility of the water-glass reaction, i.e. the rehydration of the water-glass when exposed to water, was observed. Thus, when the HPDL surface treatment is used on the AOCG it is essential that the temperature at the base of the AOCG is in excess of $100^{\circ} \mathrm{C}$.

The laser used in the study was a surgical HPDL (Diomed Limited), emitting at $810 \mathrm{~nm} \pm 20 \mathrm{~nm}$ and operating in the continuous-wave $(\mathrm{CW})$ mode with rated optical powers ranging from 0 to $60 \mathrm{~W}$. The laser beam was delivered to the work area by means of a $4 \mathrm{~m}$ long, $600 \mu \mathrm{m}$ core diameter optical fibre, the end of which was connected to a $2: 1$ focusing lens assembly mounted on the $z$ axis of a three-axis computer numerically controlled (CNC) gantry table. The AOCG was irradiated using the defocused high-order mode HPDL beam with a beam spot diameter of $1.75 \mathrm{~mm}$ and laser powers (measured at the workpiece after fibre and optics losses using a Power Wizard powermeter) of 10$45 \mathrm{~W}$. Figure 1a illustrates the typical HPDL surface

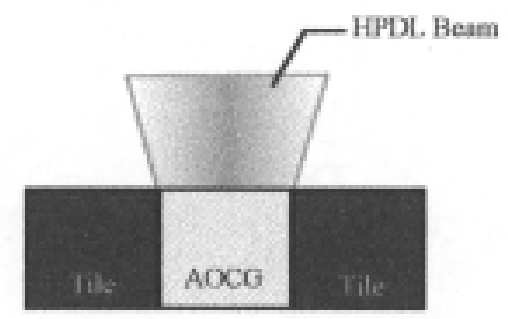

(a)

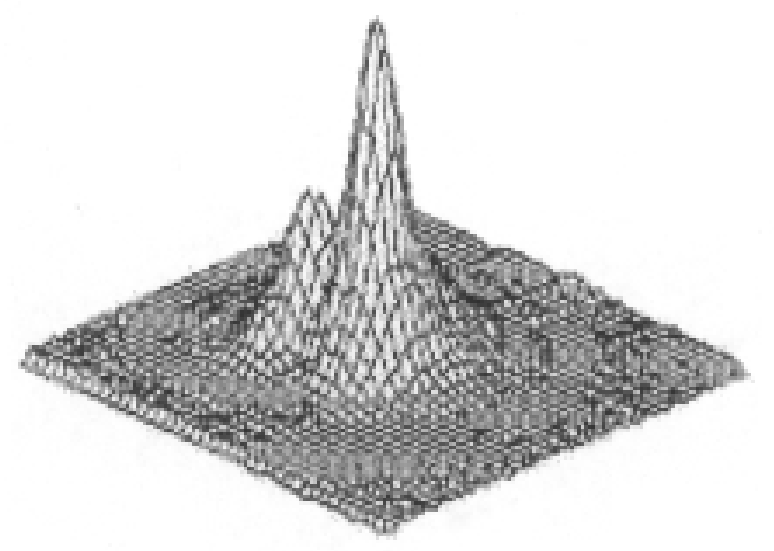

(b)

Fig. 1 (a) Schematic diagram of the HPDL surface treatment of the AOCG during the first stage of the two-stage ceramic tile grout sealing process and (b) laser beam profile of the HPDL treatment arrangement of the AOCG during the first stage of the two-stage ceramic tile grout sealing process. Here, pairs of ceramic tiles were applied on to an ordinary Portland cement (OPC) substrate in the standard manner with a conventional epoxy tile grout. The multimode defocused laser beam (Fig. 1b) was fired once across the surface of the AOCG placed in the void (standard $2 \mathrm{~mm}$ wide) between adjoining vitrified ceramic tiles. This was achieved by traversing the samples beneath the laser beam using the $x$ and $y$ axes of the $\mathrm{CNC}$ gantry table at speeds ranging from 1 to $20 \mathrm{~mm} / \mathrm{s}$, while $3 \mathrm{l} / \mathrm{min}$ of coaxially blown $\mathrm{O}_{2}$ assist gas was used to shield the laser optics as the fumes produced were removed with an extraction system.

\section{MATHEMATICAL MODEL}

In general, a steady state heat conduction problem consists of finding the temperature at any point within a specified solid whose surface has been subjected to a known set of boundary conditions. Fourier's law and Laplace's equation are utilized to assemble the temperature field equations under appropriate boundary conditions in the two-dimension Cartesian coordinates, while the FE is employed to calculate the temperature field and model the heat transfer. According to Fourier's law, general heat conduction can be described by [6]

$$
q=-k \frac{\partial t}{\partial n}=-k \nabla T
$$

where $q$ is the generated heat flux and $\nabla$ is the threedimensional operand. However, in a two-dimensional situation where $k_{x}$ and $k_{y}$ are the thermal conductivities in the $x$ and $y$ directions respectively, as is the case in question with the ceramic tile grout seal, the governing equation of the conductive heat transfer can be expressed by the rearranged Poisson equation $[\mathbf{6}, 17]$ :

$$
\frac{\partial}{\partial x}\left(k_{x} \frac{\partial T}{\partial x}\right)+\frac{\partial}{\partial y}\left(k_{y} \frac{\partial T}{\partial y}\right)+Q=\frac{1}{\alpha} \frac{\partial T}{\partial n}
$$

However, the elements comprising the ceramic tile grout seal (the AOCG, the vitreous enamel, the ceramic tiles and the OPC substrate) can be considered individually to be isotropic, within which no heat, $Q$, is generated. As such, the conductive heat transfer is given by the Laplace equation [6, 17]:

$$
\frac{\partial}{\partial x}\left(k_{x} \frac{\partial T}{\partial x}\right)+\frac{\partial}{\partial y}\left(k_{y} \frac{\partial T}{\partial y}\right)=\frac{\partial T}{\partial t}
$$

Consequently, the two-dimensional stationary temperature distribution can be derived by obtaining the solution to Laplace's equation $\left(\nabla^{2} T=0\right.$, when $k_{x}$ and $k_{y}$ are constant) with appropriate boundary conditions.

Consider Fig. 2, which shows a schematic crosssection view of the two-stage ceramic tile grout seal prior 


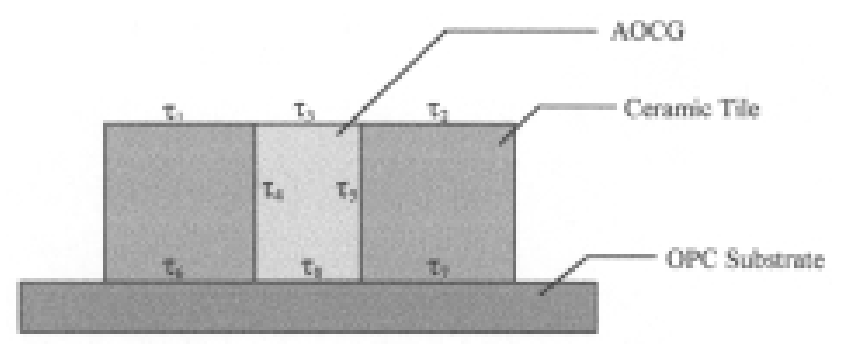

Fig. 2 Schematic profile view of the first stage of the two-stage ceramic tile grout seal showing the thermal boundaries, $\tau_{i}$ (where $i=1,2, \ldots, 8$ ), within the seal

to the first stage of the sealing process, and indicates the thermal boundaries, $\tau_{i}$ (where $i=1,2, \ldots, 8$ ), within the seal. Thus, the boundary conditions for the first stage FE model are given by

$$
\begin{array}{ll}
x, y \in \tau_{1}, \tau_{2}, & T=T_{\mathrm{o}} \\
x, y \in \tau_{3}, & T=T_{\mathrm{i}} \\
x, y \in \tau_{4}, \tau_{5}, & -k_{\mathrm{AOCG}} \frac{\partial T}{\partial n}=q_{1} \\
x, y \in \tau_{6}, \tau_{7}, & -k_{\mathrm{tile}} \frac{\partial T}{\partial n}=q_{2} \\
x, y \in \tau_{8}, & -k_{\mathrm{AOCG}} \frac{\partial T}{\partial n}=q_{3}
\end{array}
$$

in which $T$ is the transient surface temperature, $T_{\mathrm{o}}$ is the initial (original) surface temperature of the AOCG, $T_{\mathrm{i}}$ is the temperature profile of the HPDL beam incident on the AOCG and $q_{1}, q_{2}, q_{3}$ are the various resultant heat fluxes. Additionally, so as to accurately model the heat transfer within the first stage of the sealing process resulting from HPDL beam interaction, it was essential to determine the exact nature of the heat source, i.e. the laser beam characteristics, in particular the beam profile shown in Fig. 1b, thus making it possible to introduce into the model the exact shape of the heat source. Such beam characteristics were obtained using a Promotech UFF-100 laser beam analyser (LBA) [14].

In order to develop the FE models of the first and second stages of the sealing processes in the simplest and most accurate way the following important assumptions were made:

1. The latent heat effects resulting from chemical reactions in the AOCG and the surface melting caused by HPDL interaction are ignored.

2. Because of the comparatively small meltpool in relation to the entire seal, the effects of convection heating within the meltpool are assumed to be negligible.

3. The thermal properties of the elements comprising the two-stage ceramic tile grout seal (the AOCG, the vitreous enamel, the ceramic tiles and the OPC substrate) are assumed to remain constant with increasing temperature. In particular, the thermal properties of the enamel frit are assumed to be constant through the molten to the solid state.

4. For ease of analysis, the ceramic tiles in the lateral direction are considered to be semi-infinite (as verified by thermocouple readings).

5. For ease of analysis, the OPC substrate in the lateral and vertical directions is considered to be semi-infinite (as verified by thermocouple readings).

\section{FE MODEL CALCULATED RESULTS}

\subsection{FE model calculated temperatures}

By ascertaining the temperatures for the regions around the thermocouples from the nodal values calculated by ABAQUS at predetermined times, it was possible to predict the temperature through the central components (the AOCG and OPC substrate) of the two-stage ceramic tile grout seal. This procedure was carried out for both the first and second stages of the two-stage ceramic tile grout sealing process. Figure 3 shows how the temperature through the centre of the two-stage ceramic tile grout seal (through the AOCG and OPC substrate) in the first stage of the process alters with time for the varying depths of the thermocouples at a fixed power density of $1.5 \mathrm{~kW} / \mathrm{cm}^{2}$. From Fig. 3 it can be seen that the temperature typically increases with time and decreases with depth.

\subsection{FE model calculated thermal profiles}

Figures 4, 5 and 6 show the variation in temperature predicted within the two-stage ceramic tile grout seal during HPDL processing by the FE model in terms of depth and time, depth and speed and depth and power density respectively, during the first stage of the ceramic tile grout sealing process. The thermal profiles predicted are through the centre of the seal. The model shows the predicted thermal profile on the surface in one direction only, since the two-stage ceramic tile grout seal is symmetrical about the centre, and therefore the profile will be mirrored about the centre. In order for the model to represent realistically the two-stage ceramic tile grout sealing process the power density used in the simulations shown in Figs 4 and 5 was $1.25 \mathrm{~kW} / \mathrm{cm}^{2}$. This is within the optimum process parameters for the first stage of the process, being towards the lower end of the power density scale. However, in the simulation shown in Fig. 6 the interaction time used was $2.5 \mathrm{~s}$, which converts to an equivalent traverse speed of $240 \mathrm{~mm} / \mathrm{min}$ for a beam spot diameter of $1.6 \mathrm{~mm}$ and lies well within the optimum process parameters for the first stage of the process. Only the depths of the thermal profiles in the AOCG are considered, because the AOCG section in situ within the two-stage ceramic tile grout seal is 


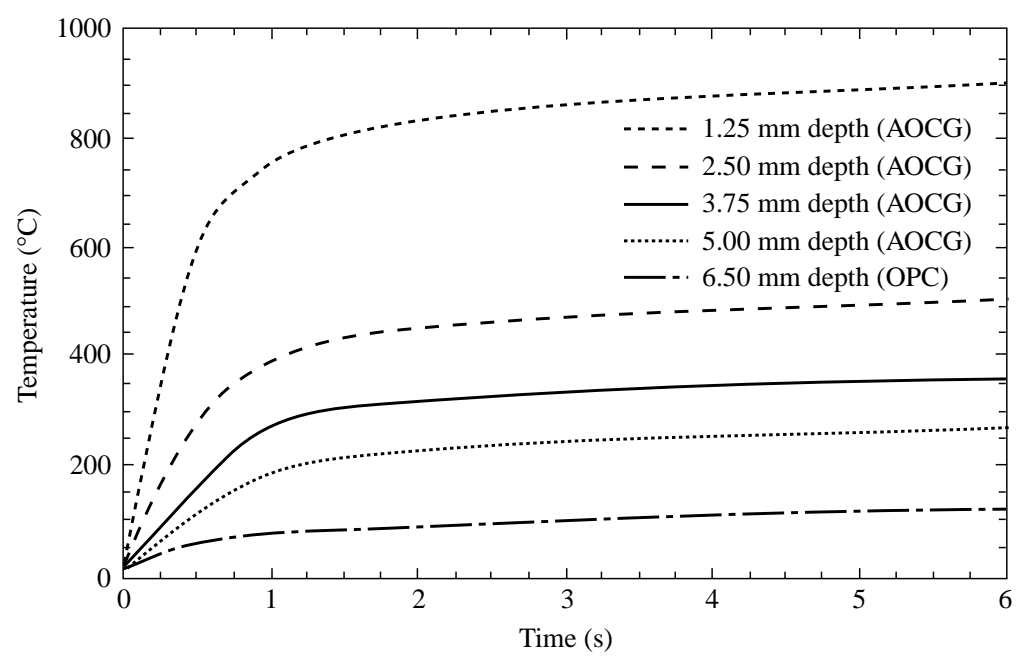

Fig. 3 FE model calculated relationship between temperature and time at various depths within the two-stage ceramic tile grout seal in the first stage of the process

relatively narrow; thus lateral changes in temperature may be deemed to be negligible.

As discussed previously, the FE model does not account for any of the reactions occurring in the AOCG during HPDL interaction, or any optical phenomena intrinsic within the sealing process. During the first stage of the process the predicted temperatures are slightly higher than the measured temperatures. Notwithstanding this, Figs 4, 5 and 6 show how the thermal profile varies with time through the centre of the AOCG and the OPC substrate. Indeed, from Figs 4, 5 and 6 the change in the thermal profile between the AOCG and the OPC substrate at around $5 \mathrm{~mm}$ can be seen.

More importantly perhaps, Figs 4, 5 and 6 show that when using a power density of $1.25 \mathrm{~kW} / \mathrm{cm}^{2}$, which lies towards the bottom end of the power density scale, the whole section of the AOCG experiences a temperature in excess of $100^{\circ} \mathrm{C}$ in an interaction time of less than $0.2 \mathrm{~s}$, therefore indicating that the complete irreversibility of the water-glass reaction throughout the whole section of the AOCG, i.e. the rehydration of the water-glass, is achieved when it is exposed to water. It was found that the highest temperature experienced by the AOCG, which occurs during the first stage of the process, is only around $200^{\circ} \mathrm{C}$, even at the maximum interaction time.

\subsection{FE model calculated process operating maps}

From a manipulation of the thermal profile data files resulting from the FE model and simultaneous cross-

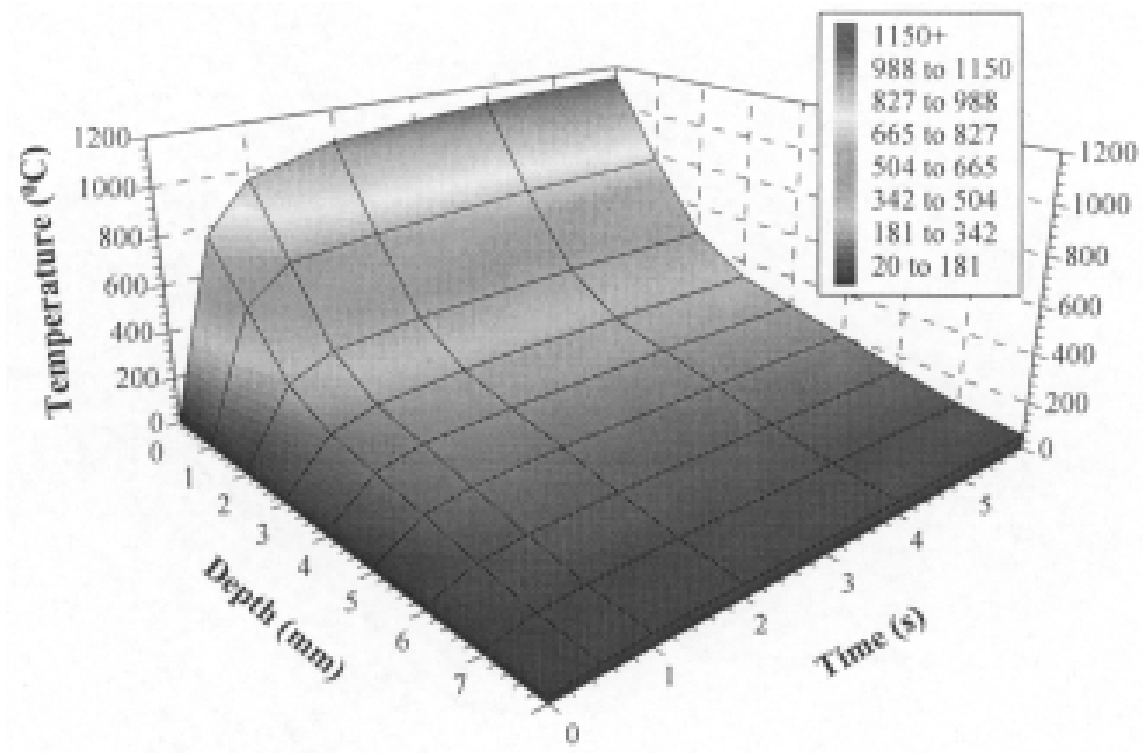

Fig. 4 FE model predicted thermal profile in relation to depth and time during the first stage of the ceramic tile grout sealing process $\left(1.25 \mathrm{~kW} / \mathrm{cm}^{2}\right.$ power density) 


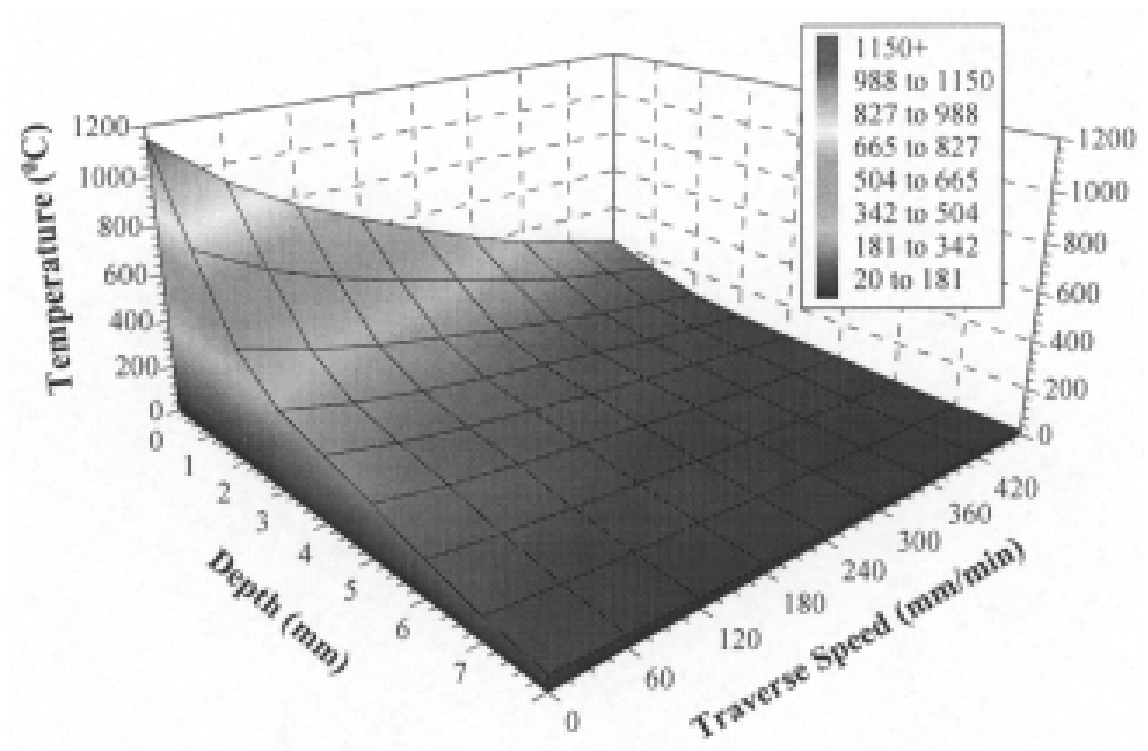

Fig. 5 FE model predicted thermal profile in relation to depth and traverse speed during the first stage of the ceramic tile grout sealing process $\left(1.25 \mathrm{~kW} / \mathrm{cm}^{2}\right.$ power density)

referencing with the thermogravimetric-differential thermal analysis (TG-DTA) results shown in Fig. 7, it was possible to generate detailed operating maps indicating the depth to which HPDL-induced chemical reactions occur within the AOCG in terms of power density and traverse speed for the first stage of the twostage ceramic tile grout sealing process. The generated operating maps predict the depth of dehydration, the depth of $\mathrm{Mg}_{3}(\mathrm{OH})_{2} \mathrm{Si}_{4} \mathrm{O}_{10}$ decomposition, the depth of vitrification, the $\mathrm{Zn}$ melt depth and the depth of the $\mathrm{Fe}_{2} \mathrm{O}_{3} \alpha-\beta$ solid state phase transformation/crystallization of $\mathrm{Na}_{2} \mathrm{O} \cdot 2 \mathrm{SiO}_{2}$. However, as has been discussed earlier, during the second stage of the sealing process the maximum temperatures reached are consistently lower than those reached during the first stage. Thus no further thermally induced chemical reactions will occur; therefore operating maps for the second stage of the sealing process are unnecessary. As before, only the depth of the thermally induced changes in the AOCG are considered because the AOCG section in situ within the two-stage ceramic tile grout is relatively narrow; thus lateral changes in temperature are deemed to be negligible. Figure 8 shows the operating map for the predicted depth of vitrification in the AOCG.

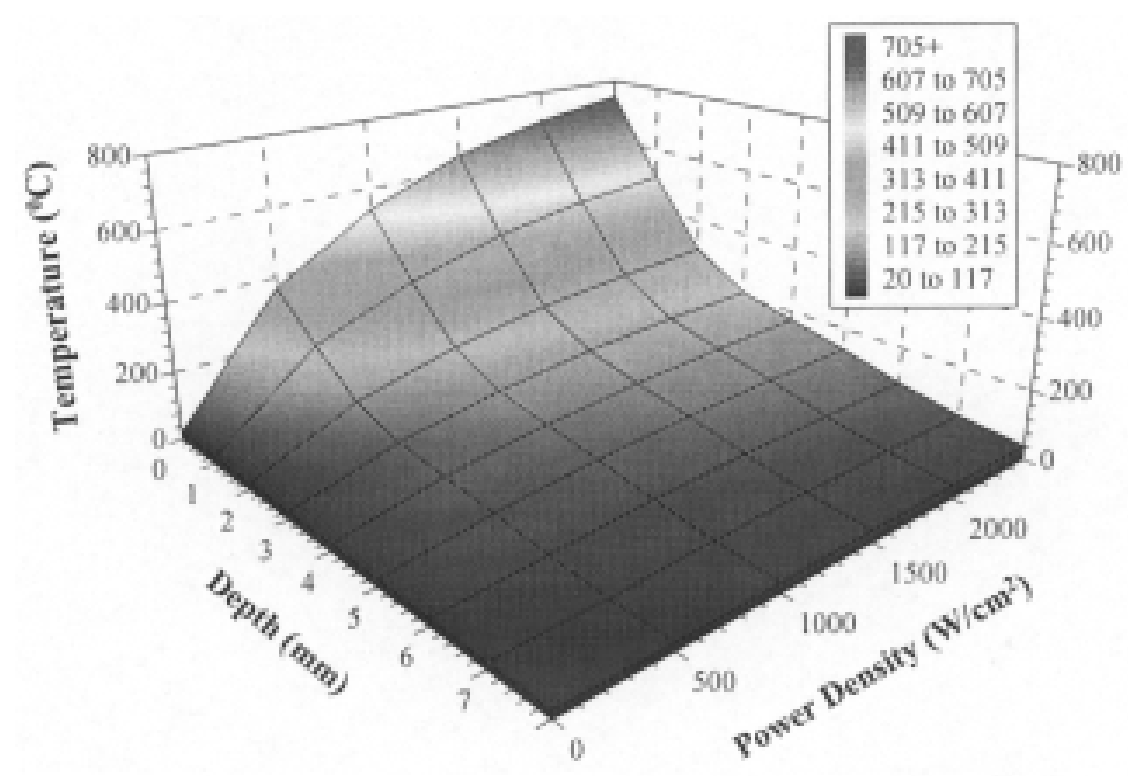

Fig. 6 FE model predicted thermal profile in relation to depth and power density during the first stage of the ceramic tile grout sealing process $(240 \mathrm{~mm} / \mathrm{min}$ traverse speed) 


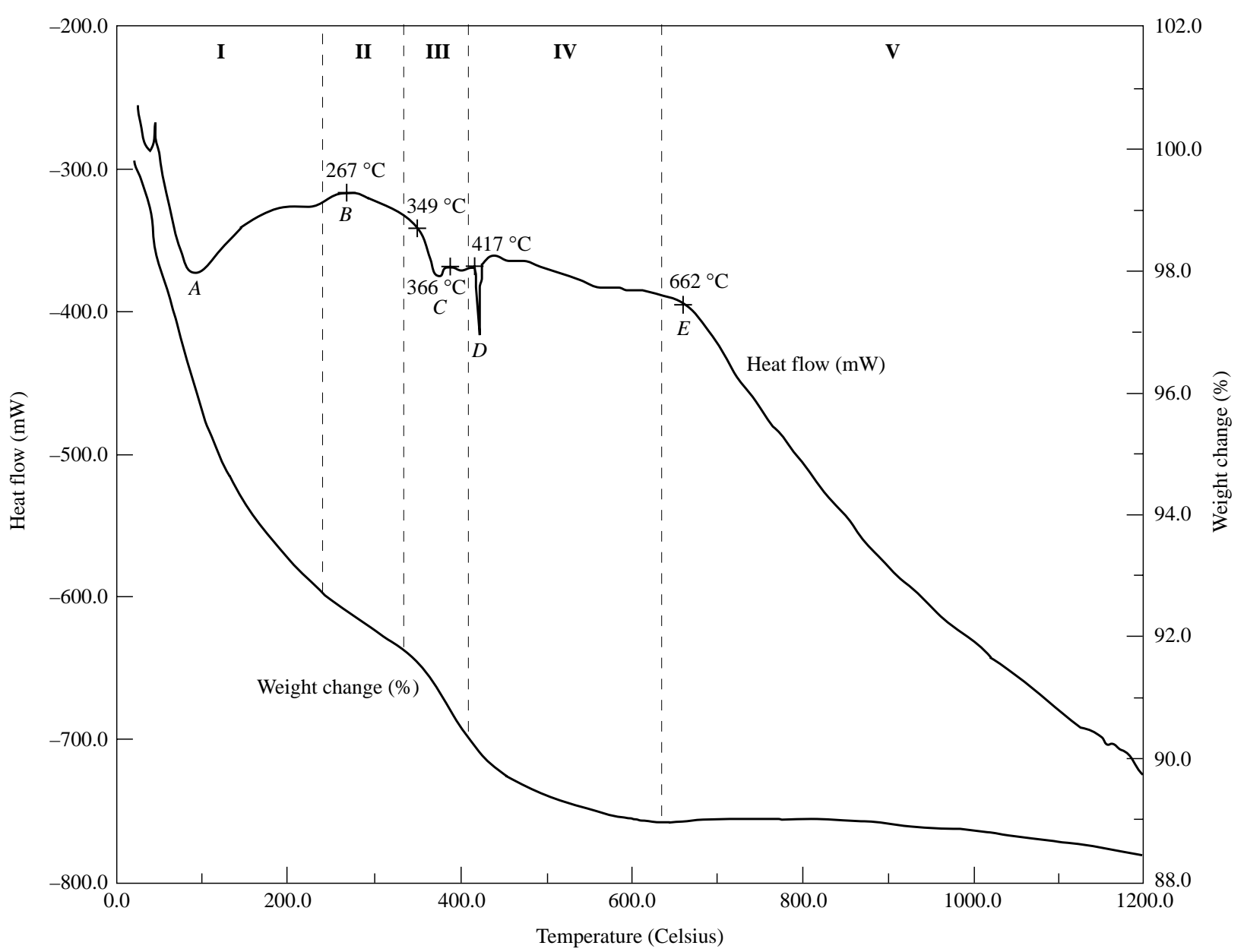

Fig. 7 TG-DTA traces for the AOCG

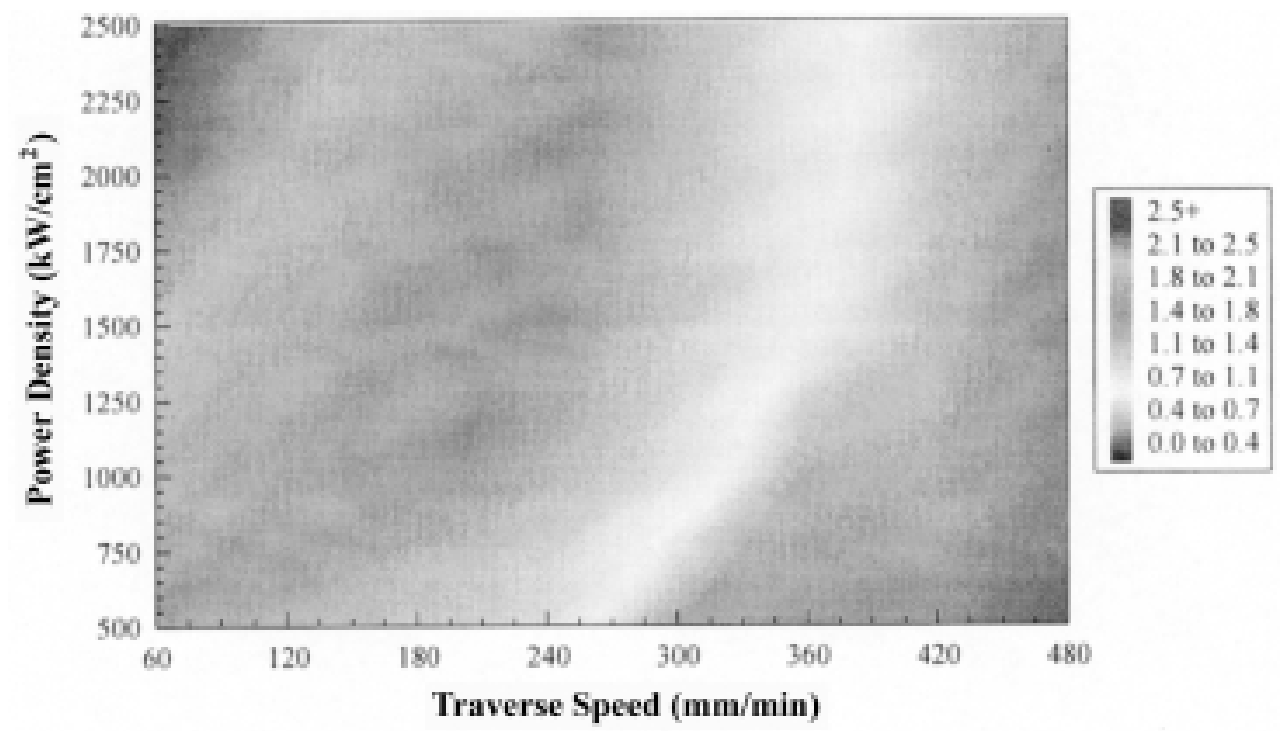

Fig. 8 Operating map for the first stage of the two-stage ceramic tile grout sealing process depicting the predicted depth of vitrification in the AOCG 


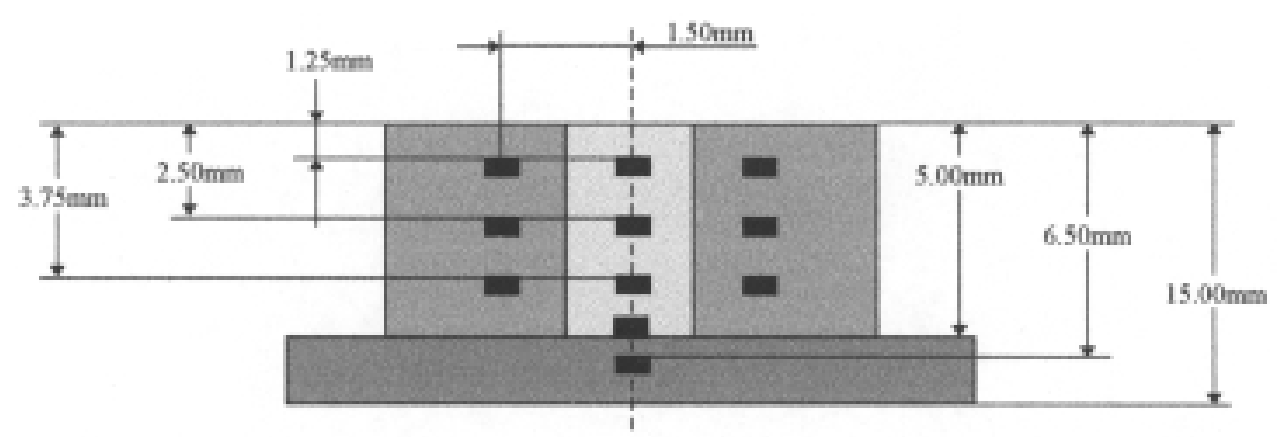

Fig. 9 Schematic of the set-up for the temperature monitoring during laser processing of the AOCG

\section{COMPARISON BETWEEN FE MODEL RESULTS AND EXPERIMENTAL RESULTS}

Standard vitrified ceramic tiles were cut into smaller pieces, $20 \mathrm{~mm} \times 20 \mathrm{~mm}$, for experimental purposes, and applied in pairs to an OPC substrate using standard epoxy tile grout. The spacing between the vitrified edges of each tile pair was $1.5 \mathrm{~mm}$. The fixed ceramic tile pieces were then allowed to set for the standard setting time of $12 \mathrm{~h}$. The tiles were then sealed by applying the AOCG into the void between adjoining ceramic tiles, flush to the surface of the tiles. The AOCG was then allowed to cure for $8 \mathrm{~h}$.

To gauge the thermal profile generated in the first stage of the ceramic tile grout sealing process, thermocouples were then inserted to either one of four predetermined depths and two predetermined distances from the centre of the ceramic tile grout seal in the samples in the manner shown in Fig. 9. The thermocouples used were type- $\mathrm{K}$ class 2 , with an accuracy of $\pm 2.5^{\circ} \mathrm{C}$ and a response time of $0.015 \mathrm{~s}$, while the thermometer used had a measurement rate of 4 readings/second, with a resolution of $0.1^{\circ} \mathrm{C}$ below $1200^{\circ} \mathrm{C}$ with an accuracy of $\pm 2{ }^{\circ} \mathrm{C}$ at $-50-1200{ }^{\circ} \mathrm{C}$. The holes for the thermocouples were drilled into the OPC substrate, the ceramic tiles and the AOCG seal using a $0.45 \mathrm{~mm}$ diameter diamondtipped drill so as to achieve as fine a hole as possible. Water cooling of the drill was employed in order that the nature of the OPC substrate, the ceramic tiles or the AOCG was not affected by the heat generated during the drilling process. The holes were then filled with thermal conducting paste prior to the insertion of the thermocouples so as to provide good thermal contact between the materials and the thermocouples. To obtain accurate temperature readings, the thermocouple pairs in each sample were attached to digital thermometers, with the thermometer readings being recorded on video along with the interaction times. The samples were irradiated for $6 \mathrm{~s}$ using a defocused HPDL beam with a power density of $1.5 \mathrm{~kW} / \mathrm{cm}^{2}$ (for a beam spot diameter of $1.6 \mathrm{~mm}$ ). The beam was aligned such that it was incident axially with the centre-line through the ceramic tile grout seal samples.

Figure 10 shows the results of the experimentally determined temperature distribution in the first stage of the ceramic tile grout sealing process, in comparison with the FE model predicted temperature distribution for one set of parameters. The results depicted in Fig. 10 are only for a single point in the centre of the AOCG at a depth of $1.25 \mathrm{~mm}$ subjected to a fixed

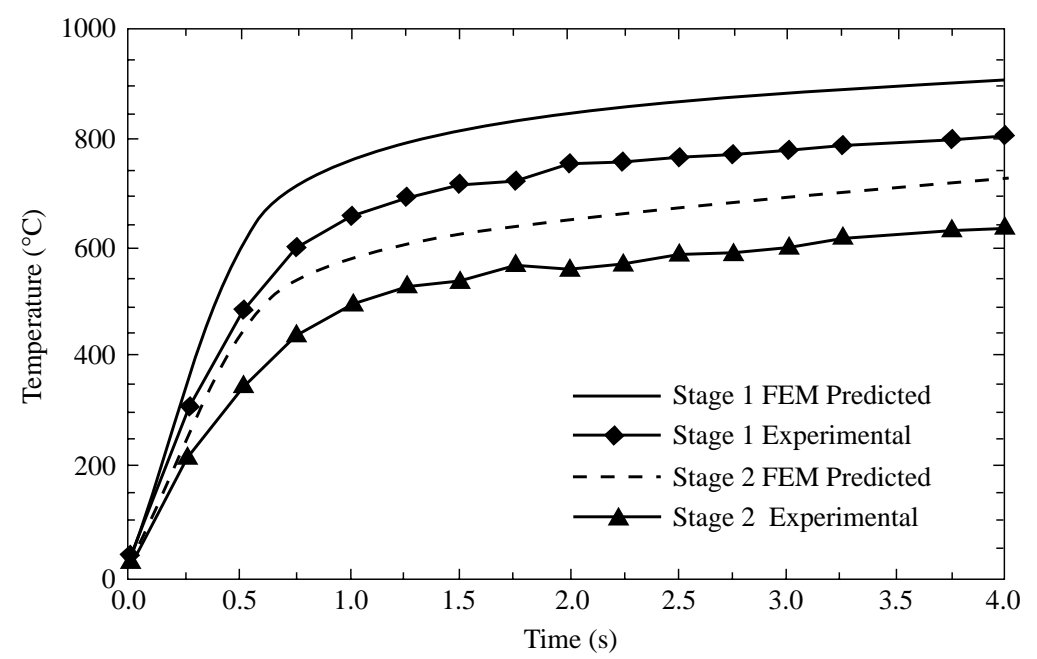

Fig. 10 Comparison between the FE model predicted and experimental temperatures for a point in the centre of the AOCG $1.25 \mathrm{~mm}$ from the surface of the seal 
Table 1 Comparison between measured and predicted depths of vitrification on the AOCG for certain laser power densities and traverse speeds

\begin{tabular}{lcc}
\hline & \multicolumn{2}{c}{ Depth of vitrification $(\mu \mathrm{m})$} \\
\cline { 2 - 3 } Laser parameters & Measured & Predicted \\
\hline $1 \mathrm{~kW} / \mathrm{cm}^{2}$ at $480 \mathrm{~mm} / \mathrm{min}$ & 370 & 420 \\
$1.25 \mathrm{~kW} / \mathrm{cm}^{2}$ at $360 \mathrm{~mm} / \mathrm{min}$ & 1025 & 1100 \\
$1.5 \mathrm{~kW} / \mathrm{cm}^{2}$ at $240 \mathrm{~mm} / \mathrm{min}$ & 520 & 585 \\
\hline
\end{tabular}

power density of $1.5 \mathrm{~kW} / \mathrm{cm}^{2}$. Figure 10 shows that for the first stage of the two-stage ceramic tile grout sealing process, the temperature distribution predicted by the FE model was consistently higher than those obtained experimentally. Nevertheless, the temperatures predicted by the FE model and those obtained experimentally were, in general, in very close agreement with one another.

Of the five operating maps generated for the AOCG [depth of dehydration, depth of $\mathrm{Mg}_{3}(\mathrm{OH})_{2} \mathrm{Si}_{4} \mathrm{O}_{10}$ decomposition, depth of vitrification, $\mathrm{Zn}$ melt depth and the depth of $\mathrm{Fe}_{2} \mathrm{O}_{3} \alpha-\beta$ solid state phase transformation/crystallization of $\mathrm{Na}_{2} \mathrm{O} \cdot 2 \mathrm{SiO}_{2}$ ], only the depth of vitrification has been considered in this study since it is the most readily verifiable for the vitrification depths observed on actual HPDL-treated AOCG samples. Table 1 shows, as was the case with the temperature profiles, that the predicted depths of vitrification observed in Fig. 8 were consistently higher than those measured [14]. Notwithstanding this, such a comparison revealed that the predicted depths of vitrification were in very close agreement with those observed on AOCG samples treated with the HPDL.

\section{DISCUSSION}

The fact that there are discrepancies between the temperatures predicted by the FE model and the temperatures recorded during experimentation indicates that some degree of inaccuracy is inherent within the FE model. This is due perhaps to the theoretical idealizations and the assumptions made, as well as the many unknown aspects involved, such as the thermocouple readings, etc. Also, since none of the laser parameters alter during the experiments it is highly probable that certain external factors influence the degree of agreement between the results. These external factors can be identified as the endothermic reactions, changes in the thermal properties of the two-stage ceramic tile grout seal components and experimental errors during the temperature monitoring.

\subsection{Endothermic reactions}

The FE model assumes there to be no latent heat effects within the components of the two-stage ceramic tile grout seal, in particular the AOCG, during the heating cycle to the steady state condition. However, since the increase in temperature resulting from HPDL interaction results in the occurrence of certain chemical reactions within the AOCG and the surface melting, latent heat effects due to the energies of these reactions (endothermic reactions) will be apparent.

If Fig. 5 is considered, then it can be seen that for the first stage of the sealing process agreement between the temperatures predicted by the FE model and the experimentally obtained temperatures hold consistently for approximately the first $1-1.5 \mathrm{~s}$ of the heating cycle to the steady state condition. Beyond this point in time, when the error between the predicted and experimental sets of temperature data ceases to be consistent, the error was seen to increase. From the experimental curves it can be seen that the temperature at which this consistent agreement ceases is around $250^{\circ} \mathrm{C}$. As the TG-DTA showed, within this temperature range considerable dehydration of the AOCG occurred. Moreover, these dehydration reactions were identified as being endothermic [14]. The dehydration reactions remove heat which is not accounted for in the FE model. Consequently, the temperatures predicted by the FE model are higher than those observed during the experiments since the model does not account for the effective heat sink arising from the endothermic reactions.

However, the TG-DTA revealed that the endothermic reactions in the AOCG occurred from around $80^{\circ} \mathrm{C}$ onwards. Accordingly, the effects of the heat sink would therefore be expected to be seen from $80^{\circ} \mathrm{C}$ onwards, whereas in Fig. 10 these effects become apparent from $250{ }^{\circ} \mathrm{C}$ onwards. It is suggested that since the difference between the actual onset of the endothermic reactions $\left(80^{\circ} \mathrm{C}\right)$ and those experimentally observed $\left(250^{\circ} \mathrm{C}\right)$ is relatively small, the rapid heating rate achieved through HPDL interaction results in the 'telescoping' of the reactions, causing the reaction temperatures to increase [18]. Furthermore, the TG-DTA indicated that the other reactions that occurred in the AOCG as the temperature increased were also endothermic, and will therefore compound the error between the temperatures predicted by the FE model and those obtained experimentally as the temperature increases. Indeed, this is the case as depicted in Fig. 10, where the complete range of temperatures and corresponding endothermic reactions in the AOCG are experienced in the first stage of the sealing process.

\subsection{Changes in the thermal properties of the amalgamated oxide compound grout}

Prominent within the assumptions of the FE model is the fact that the thermal properties of the components comprising the two-stage ceramic tile grout seal remain 
constant, in particular the thermal conductivity, $k$. However, the vitrification of the AOCG surface during the first stage of the sealing process at around $366^{\circ} \mathrm{C}$, which is an endothermic reaction, causes a change in the thermal conductivity of the affected area. However, the change is small, altering from $1.49 \mathrm{~W} / \mathrm{mK}$ before laser treatment to $1.53 \mathrm{~W} / \mathrm{mK}$ after laser treatment. Consequently, with such a small change in the thermal conductivity of the AOCG, it is reasonable to assume that the effect of this change on the FE model will be negligible. Nevertheless, when the effects of this unaccounted-for change in thermal conductivity are combined with those resulting from the same endothermic reaction, which again is unaccounted for, the resulting error may not be insignificant.

Additionally, it is assumed that the components comprising the two-stage ceramic tile grout seal are isotropic, and no direction is more favourable for the conduction of heat than any other. This is indeed the case for the AOCG. The same situation, however, does not exist with regard to the OPC substrate. This is because $\mathrm{OPC}$ is a non-uniform composite material and its thermal properties will therefore vary since the thermal properties of the cement are different from those of the aggregate pieces [19]. Also, the aggregate pieces will undergo different reactions from those of the cement matrix. The value for the OPC thermal conductivity used in the FE model represent an average for the bulk concrete. In contrast, however, the measurements of the thermocouples depend entirely on their specific positioning. Consequently, a thermocouple positioned within an aggregate piece will measure the temperature of the aggregate rather than the bulk OPC, thus affecting the average of the readings and generating a discrepancy.

\subsection{Experimental errors during temperature monitoring}

It is highly probable that experimental errors account for a significant proportion of the discrepancies observed between the temperatures predicted by the FE model and the results obtained experimentally. In particular, two areas of the experimental preparation and procedures can be identified as likely sources of experimental error. These are the accuracy of the measurement of the depth of the thermocouples and the determination of the HPDL beam characteristics.

The inaccurate measurement of the depth of the thermocouple can introduce significant errors into the experimental results. The positions of the holes drilled into the two-stage ceramic tile grout seal samples were measured relative to the surface of the samples, with the assumption being that the actual position of the thermocouple below the sample surface is the same. However, should the sample not be square or the hole not be drilled perpendicular to the surface, then an error of some millimetres in the depth and width measurements could result, since the thermocouple is only $0.3 \mathrm{~mm}$ in diameter and therefore significant at depths of only a few millimetres.

The precise characterization of the HPDL beam spot incident on the AOCG surface is essential in order to give an accurate model of the heating process. Inexact measurements of the beam profile, and thus the power intensity distribution of the beam, would lead to the FE model consistently predicting an inaccurate thermal profile. However, since the exact beam profile of the laser beam, as measured by the Promotech UFF-100 LBA and shown in Fig. 1b [14], is used in the FE model, then it can be assumed that little or no experimental error can be apportioned to the measurement of the HPDL beam characterization.

\section{CONCLUSION}

Due to the complexities of modelling the thermal behaviour of the two-stage ceramic tile grout sealing process, a numerical technique was employed which utilizes the ABAQUS finite element (FE) package. The model created generated thermal contours, as opposed to isochromes, and so allowed laser parameters such as traverse speed to be considered in the modelling, thereby facilitating a more realistic analysis. Furthermore, manipulation of the thermal profile data files predicted by the FE model resulted in the generation of operating maps which showed the extent to which the temperatureinduced chemical changes in the AOCG, which were identified in the TG-DTA, occur. Both the FE predicted temperature profiles and the operating maps were seen to be in close agreement with experimentally obtained measurements, affirming the accuracy of the FE model.

Consequently, generation of the model can facilitate the establishment of the ideal laser operating parameters necessary to ensure that both adequate surface melting of the AOCG [20] and a sufficiently high temperature $\left(>100^{\circ} \mathrm{C}\right)$ at the base of the AOCG is achieved, ensuring the complete irreversibility of the water-glass reaction.

\section{ACKNOWLEDGEMENTS}

The authors would like to express their gratitude to the EPSRC: Process Engineering Group (Grant GR/ K99770) and the EPSRC: CDP Group (CASE Award 95562556) for their financial support. Special thanks also go to Dr Osman Beg of Ove Arup and Partners and Dr Shuguang Li of UMIST for their expert advice on the subject of thermal modelling and the use of ABAQUS. 


\section{REFERENCES}

1 Taylor, G. D. Construction Materials, 1991 (Longman Scientific and Technical, London).

2 Lawrence, J., Li, L. and Spencer, J. T. A two-stage ceramic tile grout sealing process using a high power diode laser. Part I: grout development and materials characteristics. Optics and Laser Technol., 1998, 30, 205-214.

3 Lawrence, J., Li, L. and Spencer, J. T. A two-stage ceramic tile grout sealing process using a high power diode laser. Part II: mechanical, chemical and physical properties. Optics and Laser Technol., 1998, 30, 215-223.

4 Jeager, J. C. Moving sources of heat and temperature at sliding contacts. Proc. R. Soc. NSW, 1942, 76, 203-224.

5 Rosenthal, D. The theory of moving sources of heat and its application to metal treatments. Trans. ASME, 1946, 68, 849-866.

6 Carslaw, H. S. and Jeager, J. C. Conduction of Heat in Solids, 1959 (Oxford University Press, London).

7 Patankar, S. V. Numerical Heat Transfer and Fluid Flow, 1980 (Hemisphere Publishing, New York).

8 Yagla, J. J., Haag, R. S. and Scott, M. E. Laser welding analysis and experiments. J. Ship Prod., 1995, 11, 102-110.

9 Park, J. S. and Na, S. J. Heat transfer in a stud-to-plate laser braze considering filler metal movement. Weld. J., 1988, 77, 155-163.

10 Onut, S. Finite element analysis of laser forming. MSc thesis, Strathclyde University, 1993.
11 Odumodu, K. U. and Das, S. Forceless forming with a laser. Proc. ASME: Mater. Div., 1996, 74, 169-170.

12 Hsiao, S., Shimizu, H., Firth, L., Maher, W. and Masubuchi, K. Finite element modelling of laser forming. LIA Proc., 1997, 77, 31-40.

13 Mazumder, J. Overview of melt dynamics in laser processing. Opt. Engng, 1991, 30, 1208-1219.

14 Lawrence, J. Characteristics of a two-stage ceramic tile grout sealing process using a high power diode laser. $\mathrm{PhD}$ thesis, UMIST, 1999.

15 DeGarmo, E. P., Black, J. T. and Kohser, R. A. Materials and Processes in Manufacturing, 1997 (Prentice-Hall, Upper Saddle River).

16 Petzold, A. and Rohrs, M. Concrete for High Temperatures, 1970 (MacLaren and Sons, London).

17 Özisik, M. N. Heat Transfer: A Basic Approach, 1985 (McGraw-Hill, New York).

18 Warne, S. Introduction to thermal analysis. In Thermal Analysis: Techniques and Applications (Eds E. L. Charsley and S. B. Warrington), 1992, pp. 1-16 (Royal Society of Chemistry, London).

19 Gani, M. J. Cement and Concrete, 1997 (Chapman and Hall, London).

20 Lawrence, J., Li, L. and Spencer, J. T. High power diode laser modification of the wettability characteristics of an $\mathrm{Al}_{2} \mathrm{O}_{3} / \mathrm{SiO}_{2}$ based oxide compound for improved enamelling. J. Mater. Sci. Engng A, 1999, 266, 1067-1074. 
Copyright of Proceedings of the Institution of Mechanical Engineers -- Part B -Engineering Manufacture is the property of Professional Engineering Publishing and its content may not be copied or emailed to multiple sites or posted to a listserv without the copyright holder's express written permission. However, users may print, download, or email articles for individual use. 